\title{
\#MeToo: Uncovering Sexual Harassment and Assault in Sport
}

\author{
Justine J. Reel and Emily Crouch \\ University of North Carolina Wilmington
}

This year, the Journal of Clinical Sport Psychology (JCSP) reached a couple of milestones: earning an impact factor and celebrating its $12^{\text {th }}$ birthday. In December, the journal published a special issue on eating disorders in sport and exercise. At the Orlando JCSP editorial board meeting, several of us entertained the possibility of underscoring the importance of the \#MeToo movement by developing a call for papers to produce a special issue around sexual harassment in sport for the journal. To my knowledge, our journal has rarely (possibly never) published on this important topic. For me, the \#MeToo movement was especially powerful as it uncovered several painful memories from the past. I found myself experiencing a myriad of reactions including shock, anger, and fear. Like many survivors of sexual harassment in sport, I never reported these harmful experiences. In fact, one individual is still coaching and 25 years later I grapple with feelings of vulnerability. My decision is to attempt to make a positive difference in spite of this adversity. My former doctoral student and Assistant Professor, Dr. Nick Galli, studies this push through negative experiences, which is aptly named stress-related growth. When someone experiences a challenge he or she can make the decision to learn and grow as a result. Therefore, for me, this \#MeToo special issue represents a symbol of both moving on and taking action.

This special issue strives to shed light on sexual assault and harassment to begin a larger dialogue to transform our sport culture. It is our hope this collection of papers will ignite a passion in professionals - both researchers and cliniciansin the field of sport and exercise psychology. It is imperative to address this critically important topic on a regular basis and not just as a one time, special issue.

The \#MeToo movement has finally brought much-needed media attention to the age-old problem of sexual harassment in society. Last year, allegations of rampant, decades-long sexual abuse at the hands of Hollywood magnate Harvey Weinstein were hauled into the open, sending a wave of anguish across the country. Many people joined the fervent \#MeToo cry to call out authoritative figures using their power to sexually exploit subordinates. This movement has led to accusations of sexual misconduct against well-known and respected people across professions, including Bill O'Reilly, Kevin Spacey, Tom Brokaw, Bill Cosby, Matt Lauer, and others too numerous to list. It has fueled a worldwide dialogue on the range of sexual misconduct that is still pervasive in society. 
Sexual harassment has generally referred to unwanted attention of a sexual nature that may create an uncomfortable environment. In the United States sexual harassment has been categorized as either quid pro quo (i.e., benefits associated with sexual favors) or hostile environment (i.e., toxic culture that involves harassment), but sexual assault and violence are often included in the conversation (Fasting, Brackenridge, \& Walseth, 2007). Disturbingly, one-third of victims of sexual harassment or assault never share their experiences with anyone and fewer than $10 \%$ of college students report sexual assault (Taylor \& Hardin, 2017). Because many cases go unreported, it is likely the harassment continues (Fasting et al., 2007). As recently as 2016, an estimated $77 \%$ of rape and sexual assault incidents went unreported in the United States (Bureau of Justice Statistics, 2017).

\section{Sexual Harassment and Assault in Sport}

The sport environment has been recognized as a microcosm of sexual harassment and assault. Sport has been accused of being a breeding ground for sexual harassment and assault given the idealization of masculinity and violence inherent in the culture (McMahon, 2007). The Jerry Sandusky and Larry Nassar scandals of the past decade have illuminated the painful reality that child and adolescent athletes, in their tight-knit, highly-aspirational environments, are vulnerable to sexual misconduct by figures they emulate and trust. Sexual violence committed by coaches has been discussed in the literature since the 1980s and has received much attention in the news associated with the movement (Parent \& Fortier, 2018). There have been numerous examples of coaches in authority positions who were given complete access to young athletes and abused their power. Some of the more disturbing incidents have involved sexual acts with minors and have inflicted lifelong wounds on victims. Child victims of sexual abuse comprise the highest percentage of individuals with Post Traumatic Stress Disorder (PTSD), and they are significantly more likely to develop anxiety and depression, abuse drugs and alcohol, and attempt suicide (Olafson, 2011). But victims extend beyond athletes and include fellow coaches and even sport psychology consultants. Sexual violence can occur between athletes and does not discriminate by sex. Both males and females can be victims or abuse positions of authority.

Therefore, in the interest of raising awareness, this special issue features some of these courageous victims who bravely tell their stories. They paint a picture of how it is to be powerless in an environment that values athletic success or psychological well-being of a child, adolescent, or young adult. Other manuscripts highlight best practices for approaching athletes who have faced the unspeakable and are trying to move on and excel in sport. This collection of papers should be especially meaningful to clinicians and sport psychology consultants who support athletes, former athletes, and clients in the aftermath of sexual harassment and assault as well as survivors who silently harbor stories.

\section{A Call to Action}

If this special issue sparks an interest in you, please act on your passion. Conduct research and practice in this area. Be an advocate for a safe workplace. Institutions 
where sexual harassment festers - athletic organizations, colleges, businessesshould form mutual partnerships with advocates of sexual harassment prevention (Levine, 2018). Organizations can conduct agency-wide sexual harassment training to emphasize staying out of trouble legally and upholding moral and ethical standards of behavior that shun sexual misconduct (O'Leary-Kelly \& BowesSperry, 2001). Leaders can make a difference by demonstrating a zero tolerance stance against sexual harassment and assault (Nelson, Halpert, \& Cellar, 2007).

We welcome your involvement with the journal and continue to seek guest reviewers from diverse areas of expertise. If you would like to serve as a guest reviewer and/or be considered for a future editorial board position, please contact the Editor-in-Chief. If you would like to gain experience as a guest reviewer, please contact us. Further, given that JCSP desires to cover trending topics and clinical trends in the area of sport and exercise psychology, we welcome your input and ideas for special issues.

Justine J. Reel, PhD, LPC, CMPC, Editor-in-Chief Emily Crouch, MEd

\section{References}

Fasting, K., Brackenridge, C., \& Walseth, K. (2007). Women athletes' personal responses to sexual harassment in sport. Journal of Applied Sport Psychology, 19(4), 419-433. doi:10.1080/10413200701599165

Levine, E.C. (2018). Engaging the community: Building effective partnerships in sexual violence prevention. Journal of Applied Social Science, 12(2), 82-97. doi:10.1177/ 1936724418785416

McMahon, S. (2007). Understanding community-specific rape myths: Exploring student athlete culture. Journal of Women and Social Work, 22(4), 357-370. doi:10.1177/ 0886109907306331

Nelson, C.G., Halpert, J.A., \& Cellar, D.F. (2007). Organizational responses for preventing and stopping sexual harassment: Effective deterrents or continued endurance? Sex Roles, 56, 811-822. doi:10.1007/s11199-007-9239-8

Olafson, E. (2011). Child sexual abuse: Demography, impact, and interventions. Journal of Child \& Adolescent Trauma, 4(1), 8-21. doi:10.1080/19361521.2011.545811

O’Leary-Kelly, A.M., \& Bowes-Sperry, L. (2001). Sexual harassment as unethical behavior: The role of moral intensity. Human Resource Management Review, 11, 73-92. doi:10.1016/S1053-4822(00)00041-3

Parent, S., \& Fortier, K. (2018). Comprehensive overview of the problem of violence against athletes in sport. Journal of Sport and Social Issues, 42(4), 227-246. doi:10.1177/ 0193723518759448

Taylor, E., \& Hardin, R. (2017). A gap in the sport management curriculum: An analysis of sexual harassment and sexual assault education in the United States. Journal of Hospitality, Leisure, Sport \& Tourism Education, 20, 65-75. doi:10.1016/j.jhlste. 2017.04.004

U.S. Department of Justice, Office of Justice Programs, Bureau of Justice Statistics. (2017). Criminal victimization, 2016 (NCJ Publication No. 251150). Retrieved from https:// www.bjs.gov/content/pub/pdf/cv16.pdf 